\title{
ESTUDO DAS RELAÇÕES ENTRE ESTRUTURA E ATIVIDADE DE PARABENOS: UMA AULA PRÁTICA
}

\author{
João Paulo dos Santos Fernandes*, Giovanna Savino e André Cortinas Gonçalves Amarante \\ SP, Brasil \\ Milena Rodrigues de Sousa e Geane Ramos da Silva \\ Universidade Camilo Castelo Branco, R. Carolina Fonseca, 584, 08230-030 São Paulo - SP, Brasil \\ Maria Eliza Cianciulli \\ Universidade do Grande ABC, Av. Industrial, 3330, 09080-501 Santo André - SP, Brasil \\ Michelle Fidelis Corrêa e Márcio Ferrarini \\ Centro Universitário São Camilo, Av. Nazaré, 1501, 04263-100 São Paulo - SP, Brasil
}

Centro de Ciências Biológicas e da Saúde, Universidade Presbiteriana Mackenzie, R. Consolação, 930, 01302-907 São Paulo -

Recebido em 12/6/12; aceito em 7/12/12; publicado na web em 12/3/13

\begin{abstract}
STUDY OF THE STRUCTURE-ACTIVITY RELATIONSHIPS OF PARABENS: A PRACTICAL CLASS. Parabens are $p$-hydroxybenzoic acid esters widely used as preservatives. With the aim of teaching the structure-activity relationships (SAR) knowledge in a practical form, this paper proposed a practical class to view the SAR of parabens as antimicrobial agents. Methyl, ethyl, $n$-propyl, isopropyl and isopentyl paraben compounds were synthesized and their respective antimicrobial activities were assessed through determination of minimum inhibitory concentrations (MIC) against Staphylococcus aureus ATCC 25923 and Escherichia coli ATCC 25922 stains. With the MIC values, it was possible to verify theircorrelation with calculated lipophilicity $(\mathrm{Clog} \mathrm{P})$. This method can be applied in practical Medicinal Chemistry classes.
\end{abstract}

Keywords: parabens; drug synthesis; SAR.

\section{INTRODUÇÃO}

Os conservantes são usados em muitos cosméticos para aumentar a vida útil dos produtos, impedindo o desenvolvimento de microrganismos que podem causar doenças ou, simplesmente, prejudicar o bom aspecto do produto final. Um conservante ideal deve ser efetivo em uma concentração baixa e não tóxica; apresentar boa solubilidade em água; compatibilidade com outros excipientes; não ter características organolépticas adequadas; apresentar um amplo espectro de atividade para bactérias e fungos; e custo razoável. ${ }^{1}$

Dentre os conservantes mais utilizados em formulações farmacêuticas e cosméticas, destacam-se os parabenos. Parabenos são ésteres do ácido $p$-hidroxibenzoico que apresentam características como amplo espectro de atividade, boa solubilidade em água e são incolores, inodoros e insípidos. ${ }^{1,2}$ Sabe-se que a atividade antimicrobiana desses compostos aumenta com o aumento da cadeia carbônica do substituinte do éster, entretanto sua solubilidade em água decresce proporcionalmente. ${ }^{3}$ São mais ativos contra fungos do que contra bactérias. ${ }^{1}$ Entre os parabenos mais utilizados como conservantes, estão o metilparabeno (1) e o propilparabeno (3) (Figura 1).

O mecanismo de ação antimicrobiana dos parabenos é desconhecido, porém bastante complexo. Propõe-se que os parabenos apresentam ação sobre a síntese de DNA e RNA, ${ }^{4}$ sobre enzimas-chave como ATPases e fosfotransferases ${ }^{5}$ ou, ainda, sobre os mecanismos de transporte pelas membranas. ${ }^{6}$

O estudo das relações entre estrutura química e atividade biológica (REA) de moléculas bioativas é uma prática muito comum em Química Farmacêutica Medicinal. Os primeiros estudos deste tipo foram feitos por Crum-Brown e Fraser em $1869,{ }^{7}$ quando demonstraram que compostos contendo uma amina terciária (como a estricnina, morfina, atropina e nicotina) se tornavam bloqueadores neuromusculares quando metilados e, assim, transformados nos respectivos

*e-mail: joao.fernandes@mackenzie.br

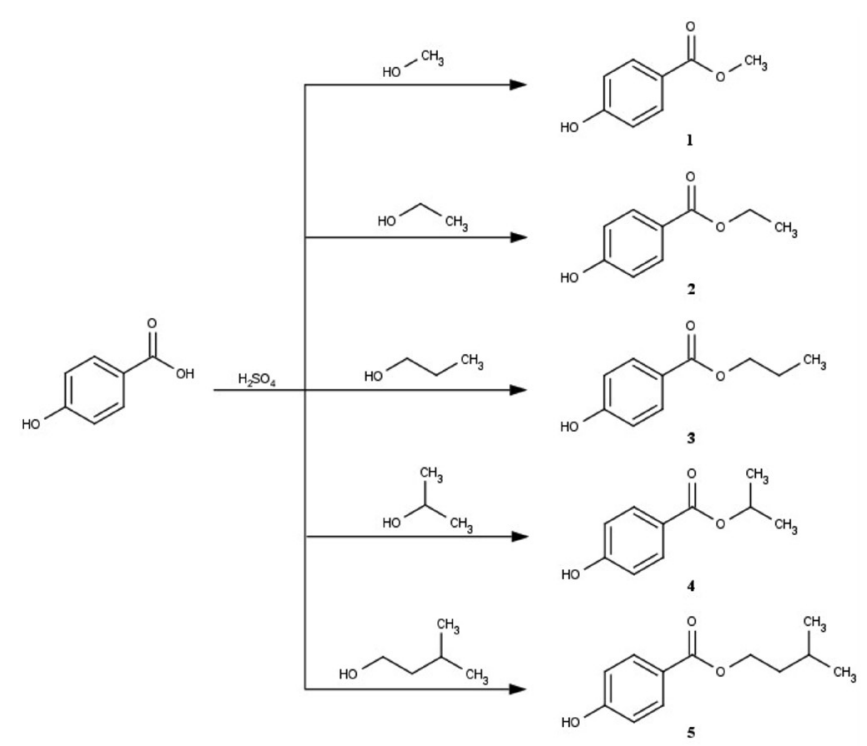

Figura 1. Esquema sintético das reações realizadas para obtenção dos parabenos $\mathbf{1}-\mathbf{5}$

quaternários de amônio. Desta forma, concluíram (mesmo que de maneira precipitada) que o grupo amônio quaternário era necessário para a atividade bloqueadora neuromuscular. ${ }^{8}$ A partir de então, a exploração de grupos funcionais em moléculas biologicamente ativas tornou-se uma prática comum entre os químicos medicinais.

O objetivo principal de estudar as REA é determinar que partes da molécula são importantes para a atividade biológica, e como a natureza dessas partes pode influenciar na mesma. Isto é feito sintetizando uma série de compostos análogos, que variam de acordo com pequenas diferenças da molécula protótipo, e avaliando a atividade desses compostos. Se a alteração ou retirada de um determinado grupo da molécula protótipo gera uma atividade baixa ou nula, conclui-se 
que o grupo é importante para a mesma. Por outro lado, se a atividade permanece inalterada ou modifica muito pouco, é porque tal grupo não tem grande influência. ${ }^{8}$

Na prática acadêmica, transmitir a importância do estudo das REA a alunos é uma tarefa às vezes não muito fácil. Muitas vezes os alunos compreendem o significado de tais "regras", porém, não conseguem facilmente vislumbrar como são determinadas na prática. Desta forma, o objetivo deste trabalho foi propor uma aula prática para a disciplina de Química Farmacêutica que demonstre todas as etapas do desenvolvimento de uma molécula bioativa, como a síntese, determinação estrutural e avaliação da atividade antimicrobiana e determinação das REA.

\section{PARTE EXPERIMENTAL}

Todos os materiais de partida utilizados na síntese foram obtidos comercialmente em pureza adequada para tal. O ponto de fusão dos produtos obtidos foi medido no aparelho de ponto de fusão capilar Sppencer Scientific modelo PFM II. Os espectros de $\mathrm{RMN}-{ }^{1} \mathrm{H}$ foram obtidos em equipamento Bruker modelo DPX-300, operando a 300 $\mathrm{MHz}$, com tetrametilsilano como referência e utilizando $\mathrm{CDCl}_{3}$ como solvente; os deslocamentos químicos foram determinados em ppm e as constantes de acoplamento em Hz.

\section{Procedimento geral para a síntese de parabenos}

Em um balão de fundo redondo equipado com condensador de refluxo e aquecimento com agitação magnética, foram adicionados $10 \mathrm{mmol}$ de ácido 4-hidróxibenzoico em $15 \mathrm{~mL}$ do álcool apropriado (ou em $15 \mathrm{~mL}$ de diclorometano, com quantidades estequiométricas do álcool isopentílico na síntese do isopentilparabeno). A seguir, 0,5 $\mathrm{mL}$ de ácido sulfúrico concentrado foram adicionados e a solução foi deixada em refluxo por $1 \mathrm{~h}$. Ao final, a solução foi neutralizada com solução de $\mathrm{Na}_{2} \mathrm{CO}_{3}$ (até $\mathrm{pH}$ 8-9) e o produto precipitado foi filtrado, lavado com água destilada e seco em dessecador. Os esquemas das reações são mostrados na Figura 1 .

\section{Metilparabeno (1)}

Sólido branco. p.f. $126-129^{\circ} \mathrm{C} . \mathrm{RMN}-{ }^{1} \mathrm{H}\left(\mathrm{CDCl}_{3}, \delta=\mathrm{ppm}, 300\right.$ $\mathrm{MHz}): 3,87$ (s, 3H, $\mathrm{CH}_{3}$ ), 6,86 (d, 2H, $\left.J=8,7 \mathrm{~Hz}, \mathrm{H}-3 / 5\right), 7,24$ (s, $1 \mathrm{H}, \mathrm{OH}), 7,93$ (d, 2H, $J=8,7 \mathrm{~Hz}, \mathrm{H}-2 / 6)$.

\section{Etilparabeno (2)}

Sólido branco. p.f. $113-117{ }^{\circ} \mathrm{C}$. $\mathrm{RMN}-{ }^{1} \mathrm{H}\left(\mathrm{DMSO}-\mathrm{d}_{6}, \delta=\mathrm{ppm}\right.$, $300 \mathrm{MHz}$ ): 1,36 (t, $3 \mathrm{H}, J=7,2 \mathrm{~Hz}, \mathrm{CH}_{3}$ ), 4,33 (q, 2H, $J=7,2 \mathrm{~Hz}$, $\mathrm{CH}_{2}$ ), 6,86 (d, 2H, $\left.J=8,7 \mathrm{~Hz}, \mathrm{H}-3 / 5\right), 7,19$ (s, 1H, OH), 7,93 (d, 2H, $J=8,7 \mathrm{~Hz}, \mathrm{H}-2 / 6)$.

\section{Propilparabeno (3)}

Sólido branco. p.f. $93-98{ }^{\circ} \mathrm{C}$. $\mathrm{RMN}-{ }^{1} \mathrm{H}\left(\mathrm{CDCl}_{3}, \delta=\right.$ ppm, 300 $\mathrm{MHz}$ ): 1,02 (t, 3H, J = 7,2 Hz, $\mathrm{CH}_{3}$ ), 1,77 (sext, $2 \mathrm{H}, \mathrm{J}=7,2 \mathrm{~Hz}$, $\left.\mathrm{CH}_{2} \underline{\mathrm{CH}}_{2} \mathrm{CH}_{3}\right), 4,30$ (t, $\left.2 \mathrm{H}, \mathrm{J}=7,2 \mathrm{~Hz}, \mathrm{OCH}_{2}\right), 6,88(\mathrm{~d}, 2 \mathrm{H}, \mathrm{J}=8,6$ $\mathrm{Hz}, \mathrm{H}-3 / 5), 7,11$ (s, 1H, OH), 7,93 (d, J = 8,6 Hz, H-2/6).

Isopropilparabeno (4)

Sólido branco. p.f. $85-88{ }^{\circ} \mathrm{C}$. $\mathrm{RMN}-{ }^{1} \mathrm{H}\left(\mathrm{CDCl}_{3}, \delta=\right.$ ppm, 300 $\mathrm{MHz}): 1,33\left(\mathrm{~d}, 6 \mathrm{H}, \mathrm{J}=6,4 \mathrm{~Hz}, \mathrm{CH}_{3}\right), 5,20$ (sept, $1 \mathrm{H}, \mathrm{J}=6,4 \mathrm{~Hz}$, $\mathrm{CH}), 6,84(\mathrm{~d}, 2 \mathrm{H}, \mathrm{J}=8,6 \mathrm{~Hz}, \mathrm{H}-3 / 5), 7,14$ (s, 1H, OH), 7,93 (d, J = $8,6 \mathrm{~Hz}, \mathrm{H}-2 / 6)$.

\section{Isopentilparabeno (5)}

Sólido levemente amarelado. p.f. $59-63{ }^{\circ} \mathrm{C}$. $\mathrm{RMN}-{ }^{1} \mathrm{H}\left(\mathrm{CDCl}_{3}, \delta\right.$ = ppm, $300 \mathrm{MHz})$ : 0,88 (d, 6H, J =6,3 Hz, $\left.\mathrm{CH}_{3}\right), 1,49-2,70(\mathrm{~m}, 3 \mathrm{H}$,
$\left.\mathrm{CH}_{2} \mathrm{CH}\right), 4,24\left(\mathrm{t}, 2 \mathrm{H}, \mathrm{J}=6,6 \mathrm{~Hz}, \mathrm{OCH}_{2}\right), 6,80(\mathrm{~d}, \mathrm{~J}=8,6 \mathrm{~Hz}, \mathrm{H}-3 / 5)$, 7,09 (s, 1H, OH), 7,93 (d, J = 8,6 Hz, H-2/6).

\section{Determinação da concentração inibitória minima (CIM)}

A CIM contra cepas de Staphylococcus aureus ATCC 25923 e Escherichia coli ATCC 25922 foi determinada utilizando-se a técnica de macrodiluição em tubos, preconizada pelo Clinical Laboratories Standards Institute. ${ }^{9}$ Foram preparadas soluções em etanol absoluto a 100,75 ou $50 \mathrm{mg} / \mathrm{mL}$ dos parabenos a serem testados (dependendo da solubilidade). A seguir, foram enumerados 12 tubos de ensaio contendo $5 \mathrm{~mL}$ de caldo Brain Heart Infusion (BHI) estéril cada. Os tubos 11 e 12 são, respectivamente, controle negativo (contendo apenas meio de cultura) e controle positivo (contendo meio e inóculo). As diluições preparadas em cada tubo são apresentadas na Tabela 1. Os alunos devem ser estimulados a calcular as concentrações finais dos compostos em cada tubo.

O inóculo foi preparado adicionando-se uma colônia isolada do microrganismo diretamente em meio de cultura e este foi incubado a $35{ }^{\circ} \mathrm{C}$ por tempo necessário para o crescimento entre 1 e $2 \times 10^{8}$ $\mathrm{UFC} / \mathrm{mL}$ (determinado espectrofotometricamente a $625 \mathrm{~nm}$ como absorbância entre 0,08 e 0,13$).{ }^{9}$ A cada tubo foram então adicionados $30 \mu \mathrm{L}$ do inóculo, e os tubos incubados a $35^{\circ} \mathrm{C}$ por $24 \mathrm{~h}$. A CIM é determinada como a menor concentração do composto capaz de inibir completamente o crescimento visível do microrganismo.

\section{Determinação do coeficiente de partição octanol/água calculado $(\mathbf{C l o g} \mathbf{P})$}

As estruturas dos parabenos obtidos foram construídas no programa MarvinBeans, ${ }^{10}$ e o ClogP determinado pelo plugin $\log \mathrm{P}$. O programa permite calcular o $\log \mathrm{P}$ através dos métodos de Viswanadhan et al., Klopman et al. e da base de dados do PhysProp, e fazer uma média ponderada dos valores. ${ }^{10}$ Neste trabalho, o peso de cada metodologia seguiu as configurações padrão do programa, sendo iguais para cada metodologia de cálculo.

\section{RESULTADOS E DISCUSSÃO}

Os experimentos realizados são feitos utilizando recursos comuns de laboratórios de aula prática (com exceção do equipamento de $\mathrm{RMN}$ ) e reagentes de baixo custo. Como a proposta tem objetivo de aula prática, o custo é um fator relevante para a viabilidade da mesma. Entretanto, cabe ressaltar que são necessários pelo menos dois laboratórios e, desta forma, os procedimentos devem ser divididos para serem realizados em dias diferentes. Em nossa experiência, dividimos a aula em quatro momentos: síntese dos compostos (realizado em laboratório de química ou outro apropriado para síntese orgânica); discussão dos espectros de RMN e determinação do ponto de fusão dos produtos (realizado em laboratório de química); determinação da atividade antimicrobiana (realizado em laboratório de microbiologia); cálculo do $\log \mathrm{P}$ e construção do gráfico de correlação (realizado em laboratório de informática). Sugerimos a divisão da turma em 5 grupos, sendo que cada grupo trabalhará com um composto desde a síntese até a determinação da atividade antimicrobiana. Os resultados devem ser compartilhados com os outros alunos, de forma que todos os alunos da sala devem ter acesso aos resultados obtidos no último momento, quando se realiza a parte computacional do experimento.

Os parabenos sintetizados no procedimento anteriormente descrito usam como estratégia sintética a reação de esterificação de Fischer. ${ }^{11}$ Tal reação baseia-se na ativação da carbonila com catalizador ácido, que favorece o ataque nucleofílico do álcool reagente. O mecanismo da reação deve ser discutido com os alunos, de forma 
Tabela 1. Diluições realizadas a partir da solução-teste

\begin{tabular}{|c|c|c|c|c|c|c|c|c|c|c|}
\hline & \multicolumn{10}{|c|}{ Tubos } \\
\hline & 1 & 2 & 3 & 4 & 5 & 6 & 7 & 8 & 9 & 10 \\
\hline Solução teste $(\mu \mathrm{L})$ & 200 & 180 & 160 & 140 & 120 & 100 & 80 & 60 & 40 & 20 \\
\hline
\end{tabular}

a avaliar possíveis alternativas para aumentar o rendimento sintético. Deve ser levada em conta nessa discussão a quantidade utilizada dos reagentes, bem como o custo de cada um deles e a viabilidade na etapa de purificação. ${ }^{11} \mathrm{O}$ mecanismo da esterificação de Fischer é apresentado na Figura 2. Na reação de obtenção do isopentilparabeno, pode-se discutir a importância da estequiometria na etapa de purificação, já que o álcool isopentílico apresenta alto ponto de ebulição $\left(\sim 131^{\circ} \mathrm{C}\right)$ e solubilidade semelhante ao produto obtido.

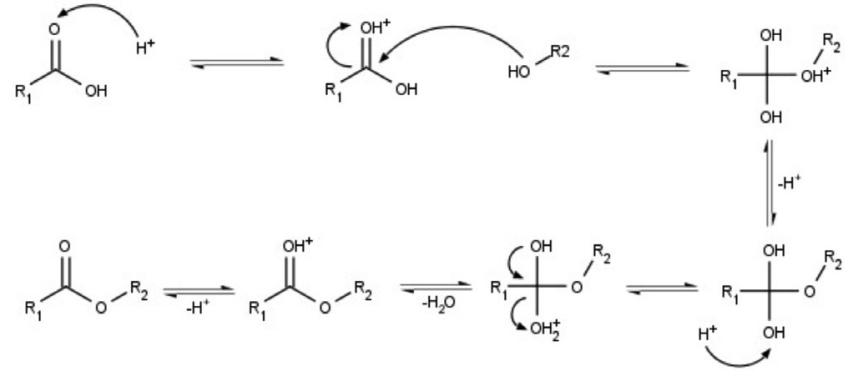

Figura 2. Mecanismo geral da esterificação de Fischer

Após os procedimentos sintéticos, a provável formação do produto desejado pode ser verificada pela simples verificação do ponto de fusão e comparação com os dados da literatura. ${ }^{12}$ Para confirmar a estrutura dos produtos, pode ser realizada uma análise de $\mathrm{RMN}-{ }^{1} \mathrm{H}$ e de suas características físicas, como ponto de fusão e solubilidade. Os parabenos utilizados são moléculas simples que permitem aos alunos a fácil verificação dos sinais referentes aos prótons da cadeia lateral, bem como suas integrais, multiplicidade e acoplamentos. Esse tipo de experimento permite ao aluno vislumbrar de maneira cinestésica a utilidade da RMN para a determinação estrutural de moléculas orgânicas, bem como o desenvolvimento de conhecimento inicial sobre a interpretação de espectros de hidrogênio.

Com a estrutura dos compostos determinada, pode ser realizada a etapa de avaliação da atividade biológica. Para facilitar a determinação das REA com relação direta, a unidade de concentração da CIM foi transformada para unidade milimol/L. Diante dos resultados obtidos (Tabela 2), é possível definir algumas REA desses compostos. Como pode ser observado na Tabela 2, quanto maior a cadeia alquílica do éster, maior a atividade antimicrobiana. Esses dados corroboram as REA reportadas na literatura, ${ }^{1,2}$ porém, o aluno pode visualizar como é realizado o raciocínio para determinação das mesmas. Além disso, pode-se observar que os parabenos realmente são compostos de amplo espectro, ${ }^{1}$ uma vez que têm atividade semelhante em $S$. aureus (Gram-positiva) e E. coli (Gram-negativa).

Tabela 2. Resultados da CIM e do $\operatorname{Clog} P$ para os parabenos avaliados

\begin{tabular}{lccc}
\hline Composto & $\begin{array}{c}\text { CIM S. aureus } \\
(\mathrm{mmol} / \mathrm{L})\end{array}$ & $\begin{array}{c}\text { CIM E. coli } \\
(\mathrm{mmol} / \mathrm{L})\end{array}$ & ClogP \\
\hline Metilparabeno (1) & 15,18 & 13,34 & 1,67 \\
Etilparabeno (2) & 4,75 & 4,75 & 2,03 \\
Propilparabeno (3) & 4,38 & 4,38 & 2,55 \\
Isopropilparabeno (4) & 4,38 & 4,38 & 2,45 \\
Isopentilparabeno (5) & 3,79 & 3,79 & 3,28 \\
\hline
\end{tabular}

Um dado não relatado na literatura, mas que pode ser definido através destes experimentos, é que a ramificação da cadeia alquílica não altera de maneira significativa a atividade antimicrobiana, uma vez que o propilparabeno e o isopropilparabeno apresentaram a mesma CIM, porém, ambos os compostos apresentam lipofilicidade semelhante. Diante disso, os alunos são encorajados a calcular o $C \log P \operatorname{dos}$ compostos e relacioná-lo com a atividade antimicrobiana. Isso pode ser feito através da construção de um simples gráfico de correlação e sua posterior visualização (Figura 3). Para manter a linearidade, os valores de CIM devem ser transformados para unidade mol/L e, a seguir, em pCIM (-logCIM). O Clog $P$ pode ser facilmente obtido através de vários programas disponíveis na internet, como o MarvinBeans, ${ }^{10}$ utilizado neste trabalho, ou outros como Molinspiration, ${ }^{13}$ ALOGPS $^{14}$ e Osiris. ${ }^{15}$ Os dados do $C \log P$ dos compostos são apresentados na Tabela 2. Assim, pode ser levantada uma discussão da importância do $\log P$ para a atividade biológica desses compostos.

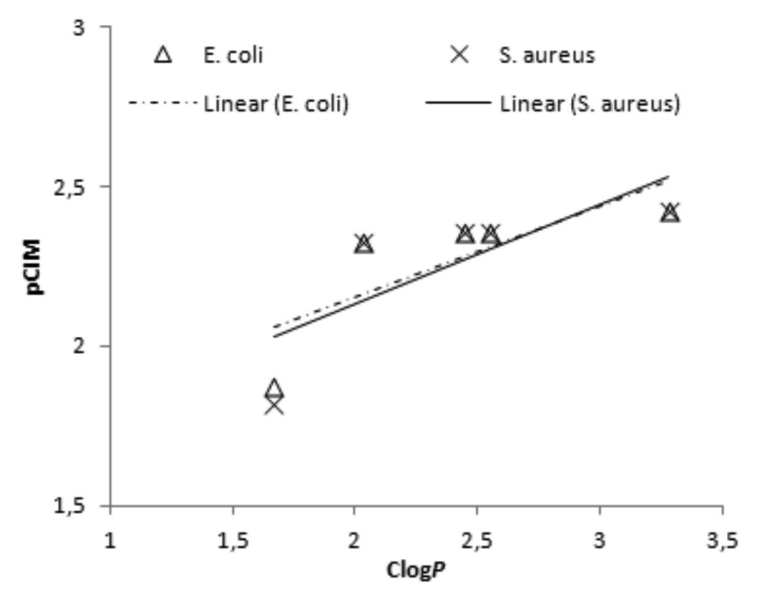

Figura 3. Gráfico de correlação entre o ClogP e o pCIM para S. aureus e E. coli dos compostos sintetizados

\section{CONCLUSÃO}

A partir da experiência realizada com alunos de graduação, é possível concluir que o experimento apresentado é uma atividade prática e, principalmente, de baixo custo para a apresentação dos processos envolvidos no desenvolvimento de fármacos, especificamente das etapas de síntese, purificação, caracterização, determinação da atividade biológica e das REA de compostos bioativos.

\section{AGRADECIMENTOS}

Ao Prof. Dr. M. J. Politi (IQ-USP) pela disponibilização das análises de $\mathrm{RMN}-{ }^{1} \mathrm{H}$ e ao empenho dos alunos envolvidos em todas as etapas do trabalho.

\section{REFERÊNCIAS}

1. Aulton, M. E.; Delineamento de Formas Farmacêuticas, $2^{\mathrm{a}}$ ed., Artmed: Porto Alegre, 2005; Pinto, T. J. A.; Kaneko, T. M.; Ohara, M. T.; Controle Biológico de Qualidade de Produtos Farmacêuticos, Correlatos e Cosméticos, $2^{\mathrm{a}}$ ed., Atheneu: São Paulo, 2003. 
2. Soni, M. G.; Burdock, G. A.; Taylor, S. L.; Greenberg, N. A.; Food Chem. Toxicol. 2001, 39, 513.

3. Fukahori, M.; Akatsu, S.; Sato, H.; Yotsuyanagi, T.; Chem. Pharm. Bull. 1996, 44, 1567.

4. Nes, I. F.; Eklund, T.; J. Appl. Bacteriol. 1983, 54, 237.

5. Ma, Y.; Marquis, R. E.; Lett. Appl. Microbiol. 1996, 23, 329.

6. Freese, E.; Sheu, C. W.; Galliers, E.; Nature 1973, 241, 321; Kamaraju, K.; Sukharev, S.; Biochemistry 2008, 47, 10540.

7. Crum Brown, A.; Fraser, T.; Trans. Roy. Soc. Edinburgh 1869, 25, 693.

8. Knittel, J. J.; Zavod, R. M. Em Foye's Principles of Medicinal Chemistry; Lemke, T.; Williams, D.A., eds.; $6^{\text {th }}$ ed., Lippincott Williams \& Wilkins: Philadelphia, 2007, chap. 2; Patrick, G. L.; An Introduction to Medicinal Chemistry, $4^{\text {th }}$ ed., Oxford University Press: Oxford, 2009.

9. Clinical Laboratory Standards Institute; Methods for Dilution Antimicrobial Susceptibility Tests for Bacteria That Grow Aerobically, $7^{\text {th }}$ ed., CLSI: Wayne, 2006
10. Chemaxon Ltd.; MarvinBeans version 5.3, Budapeste, Hungria, 2010; Viswanadhan, V. N.; Ghose, A. K.; Revankar, G. R.; Robins, R. K.; J. Chem. Inf. Comput. Sci. 1989, 29, 163; Klopman, G.; Li, J.; Wang, S.; Dimayuga, M.; J. Chem. Inf. Comput. Sci. 1994, 34, 752.

11. Fischer, E.; Speier, A.; Chemische Berichte 1895, 28, 3252; March, J.; Advanced Organic Chemistry: Reactions, Mechanisms and Structure, John Wiley \& Sons: New York, 1992; Solomons, T. W. G.; Fryhle, C. B.; Química Orgânica, LTC: Rio de Janeiro, 2009.

12. O'Neil, M. J., ed.; The Merck Index: An Encyclopedia of Chemicals, Drugs, and Biologicals, 14 ${ }^{\text {th }}$ ed., Merck: New Jersey, 2006.

13. http://www.molinspiration.com/cgi-bin/properties, acessada em Fevereiro 2013

14. http://www.vcclab.org/lab/alogps/, acessada em Fevereiro 2013.

15. http://www.organic-chemistry.org/prog/peo/, acessada em Fevereiro 2013. 